\title{
Cryptorchid testicular tumour presenting as an acute abdomen in an infant
}

\author{
Rick R. Van Rijn • Johannes H. M. Merks
}

Received: 18 December 2009/Revised: 15 January 2010/Accepted: 19 January 2010/Published online: 30 April 2010

(C) The Author(s) 2010. This article is published with open access at Springerlink.com

We present a 3-month-old baby with a cryptorchid left testicle who was referred to our institution with fever, anorexia, abdominal distension and right lower quadrant abdominal tenderness. There had been similar clinical signs 6 weeks earlier, but no imaging had been performed. Abdominal radiograph showed a small area of calcification in the right lower quadrant (Fig. 1). US showed a partly solid and partly cystic circumscript mass with a small focus of calcification (arrow) in the right iliac fossa (Fig. 2). On Doppler US no flow was detected.

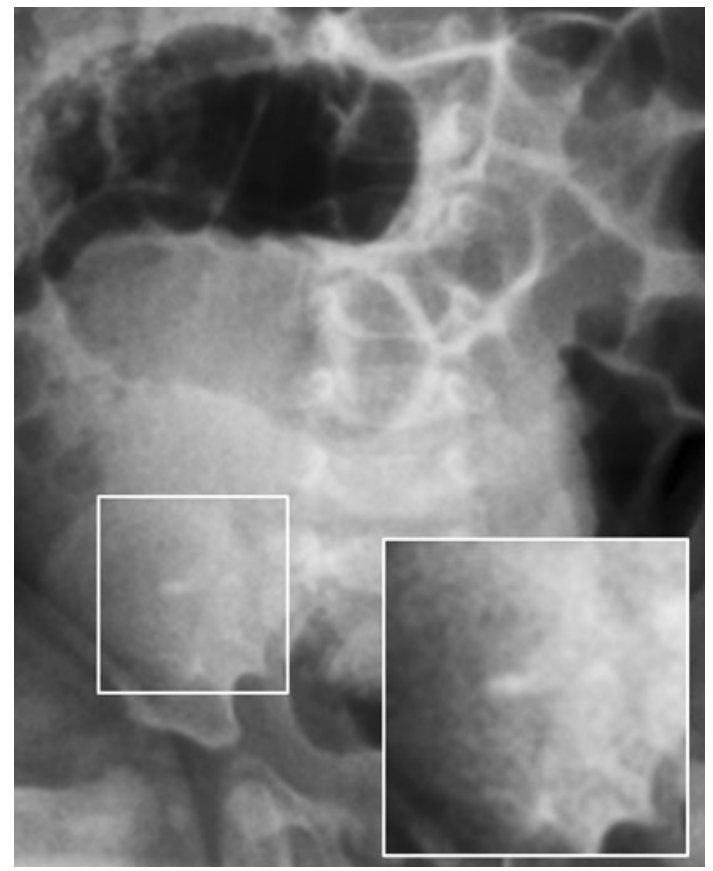

Fig. 1 Plain abdominal radiograph

R. R. Van Rijn $(\bowtie)$

Department of Radiology,

Emma Children's Hospital / Academic Medical Centre,

Amsterdam Meibergdreef 9,

1105 AZ Amsterdam, The Netherlands

e-mail: r.r.vanrijn@amc.uva.nl

\section{J. H. M. Merks}

Department of Paediatric Oncology, Academic Medical Center,

Amsterdam, The Netherlands

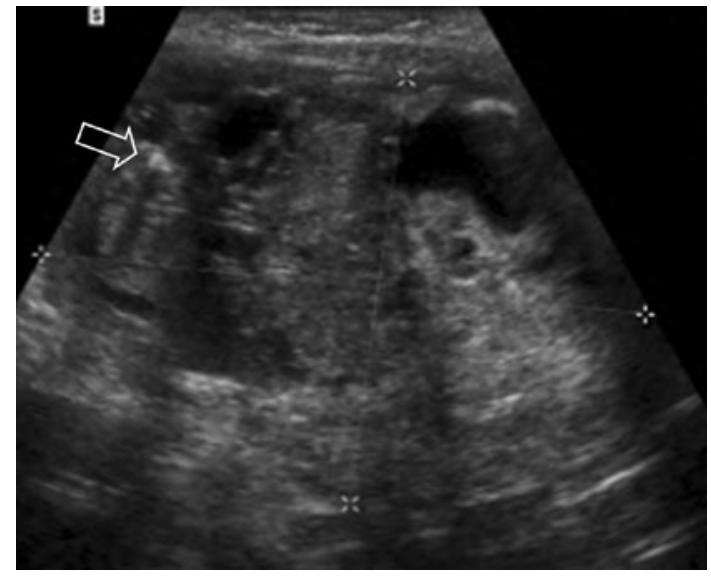

Fig. 2 US image of the tumour

The diagnosis of a tumour arising in a torqued cryptorchid left testicle was postulated. At surgery the left testicle, containing a mass, was found in the right iliac fossa. Histopathological examination showed an immature teratoma in a torqued cryptorchid testicle. In retrospect, alpha-1fetoprotein on the day of admission was $4,907 \mu \mathrm{g} / \mathrm{l}$ (normal range $0-10)$; it normalized after resection of the tumour.

It is well known that the risks of developing testicular cancer as well as torsion are increased in cryptorchid testicles $[1,2]$. Although previously reported in the literature, the presentation of this case is relatively rare and initially the diagnosis was missed.

IRB approval to publish this case was waived.

Open Access This article is distributed under the terms of the Creative Commons Attribution Noncommercial License which permits any noncommercial use, distribution, and reproduction in any medium, provided the original author(s) and source are credited.

\section{References}

1. Herrinton LJ, Zhao W, Husson G (2003) Management of cryptorchism and risk of testicular cancer. Am J Epidemiol 157:602-605

2. Wright JE (1986) Impalpable testes: a review of 100 boys. J Pediatr Surg 21:151-153 